\title{
Spontaneous subarachnoid hemorrhage in the emergency department
}

\author{
Diego Garbossa, Marco Fontanella, Alessandro Ducati, Chiara Fronda, Pierpaolo Panciani, \\ Riccardo Fornaro, Fulvio Tartara, Emanuela Crobeddu Nicola Marengo
}

Department of Neuroscience, Division of Neurosurgery, University of Turin

\section{Abstract}

Subarachnoid hemorrhage (SAH) is one of the major cause of mortality for stroke. The leading cause is the rupture of an intracrnial aneurym. Acute aneurysmal subarachnoid hemorrhage (SAH) is a complex multifaceted disorder that plays out over days to weeks.

The development of aneurysms is mainly due to a hemodynamic stress. Considerable advances have been made in endovascular techniques, diagnostic methods, and surgical and perioperative management guidelines. Rebleeding remains the most imminent danger until the aneurysm is excluded from cerebral circulation. The only effective prevention of rebleeding is repair the aneurysm; choosing the right way with surgical or an endovascular approach. Outcome for patients with SAH remains poor, with population-based mortality rates as high as $45 \%$ and significant morbidity among survivors. In this work we analyzed the diagnostic-therapeutic course of patients presenting SAH. We analyzed the types and the occurrence of complications. We present two cases report to better demonstrate that treatments for specific patients need to be individualized.

\section{Sintesi}

L'emorragia sub aracnoidea è una delle più importanti cause di morte di infarto cerebrale. Nella maggior parte dei casi è correlata con la rottura di un aneurisma intracranico. L'ESA è una patologia multifattoriale che presenta un decorso variabile da giorni a settimane.

lo sviluppo di un aneurisma intracranico è principalmente dovuto a stress emodinamico. Sono stati compiuti numerosi progressi nelle tecniche endovascolari, nei metodi diagnostici e nelle linee guida del trattamento pre-operatorio e chirurgico. Il risanguinamento rimane il pericolo più imminente sino all'esclusione dell'aneurisma dal circolo. L'unica prevenzione efficace per il risanguinamento è il trattamento dell'aneurisma, per via endovascolare o chirurgica. Generalmente, per i pazienti con ESA rimane un poor oucome, con un tasso di mortalità sino al 45\% e morbidità significativa tra I sopravviventi. In questo lavoro, abbiamo analizzato l'iter diagnostico-terapeutico dei pazienti con ESA. Abbiamo, inoltre, analizzato il tipo e la frequenza delle complicanze. Presentiamo due case report per meglio dimostrare come il trattamento debba essere individualizzato per il singolo paziente.

\section{Introduction}

The clinical presentation of non traumatic subarachnoid hemorrhage (SAH) is very heterogeneous. It varies from simple headache to coma. Often patient presents to emergency department with severe headache (97\%), vomiting, neck pain and photofobia. Less severe are symptoms more difficult is the diagnosis. Common symptoms: headache, vomiting, neck pain, photofobia, meningismus (rigor), neurological focal deficit and loss of consciousness. The patient clinical outcome depends in part from a correct and quick diagnosis. 10-15\% of patients die before reaching medical care. 30 day mortality rate was $46 \%$ in one series (1), and in others over half the patients died within 2 weeks of their SAH. $25 \%$ of patients presenting acute, severe and paroxysmal headache have SAH. Differential diagnosis: crash migraine, benign orgasmic cephalgia, reversible cerebral vasocontrictive syndrome.

\section{Epidemiology}

In the United States over 30.000 people per year has experience a SAH. Intracranial aneurysms are found in $2 \%$ to $5 \%$ of all autopsies but the population incidence of rupture is only 2-20 of 100,000 individuals per year in USA (2). The Italian incidence is 7-8 on 100000 people per year. In over 40-year old population hemorrhage is more frequent in women than men (ratio, 3:2) (3), but the reverse is true in those younger than 40-year. The peak of incidence is from 50 and 60 years old (3). Risk factors for SAH: hypertension, cigarette smoking, alcohol abuse and a history of SAH in first-degree relatives (4). The genetical asset is not completely known. Nevertheless, an hereditary is supposed. Indeed, the incidence of aneurysms in familial group is $10,5 \%$ compared to $6,8 \%$ in the general population (5). 


\section{Etiology}

- Rupture of intracranial aneurysms (75-80\%).

- Cerebral arteriovenous malformation (4-5\%).

- Vasculitides that involve the CNS.

- Tumor (rare).

- Cerebral artery dissection (carotid or vertebral).

- Rupture of superficial artery.

- Coagulation disorders.

- Dural sinus thrombosis.

- Cervical or upper thoracic arteriovenous malformation.

- Cocaine abuse.

- Pitutitary apoplexy.

- Pretruncal non aneurysmal SAH (14-22\%).

\section{Cerebral aneurysms}

The $85 \%$ of aneurysms occurs in the anterior circle of Willis. Only about $15 \%$ of aneurysms occurs in the posterior (vertebro-basilar) circulation.

The most common sites of ruptured aneurysms are $(5,6)$ :

- Posterior communicating artery from the internal carotid artery (41\%).

- Anterior communicating artery/anterior cerebral artery (34\%).

- Middle cerebral artery (20\%).

- Up to $20 \%$ of patients have multiple aneurysms.

The development of aneurysms is mainly due to hemodynamic stress. Atherosclerosis and hypertension are acquired factors involved in growth and rupture of the lesions (7). The association of heritable disorders of connective and developement of SAH covers only a minority of SAH cases. Polycystic kidney disease is the most common heritable disorder associated with SAH ( $2 \%$ of all patients) (3).

\section{Presentation}

The presentation of an acute aneurysm rupture is the instantaneous onset of a severe headache, that is usually described as the "worst headache of life" and is often followed by several symptoms and neurological signs $(5,8)$ :

- Nausea.

- Vomiting.

- Syncope followed or not by the loss of consciousness.

- Focal neurologic signs. They are unusual, but may occasionally be seen due to mass effect from a giant aneurysm, parenchymal hemorrhage, subdural hematoma, or a large localized subarachnoid clot. In addition, third and sixth cranial nerve palsies may be present respectively because of aneurysmal compression of the nerve or increased intracranial pressure.

- Seizures at onset may be reported, but many of these episodes do not represent true epileptic events but simple abnormal posturing.

\section{Diagnosis}

A CT scan is usually performed to confirm a suspicion of SAH. Blood appears as a high-density signal in the basal cisterns. CT may be falsely negative if the volume of blood is very small, or if the hemorrhage occurred several days prior, or if the hematocrit is extremely low. The accuracy in detecting a hemorrhage depends on the quantity of blood invading subarachnoid space and the time from hemorrhage. The CT sensivity is $98 \%$ in the first 12 hours after SAH, $93 \%$ at 24 hours and $71 \%$ in the first week (9). If CT scan is negative and the suspicion of SAH remains strong, a lumbar puncture should be performed. The presence of xanthochromia may be helpful in distinguishing a traumatic lumbar puncture from a true SAH, especially if it is detected by spectrophotometry (10). The amount of subarachnoid blood is an important predictor of vasospasm risk (Fiher scale - Table 1) (11).

Table 1. The Fisher scale classifies the appearance of SAH on CT scan,

Fisher scale:

1. no blood

2. less $1 \mathrm{~mm}$ thickness of blood;

3. more $1 \mathrm{~mm}$ thickness of blood;

4. any amount of blood with ventricular bleeding and,or cerebral hematoma. 


\section{clinica e terapia}

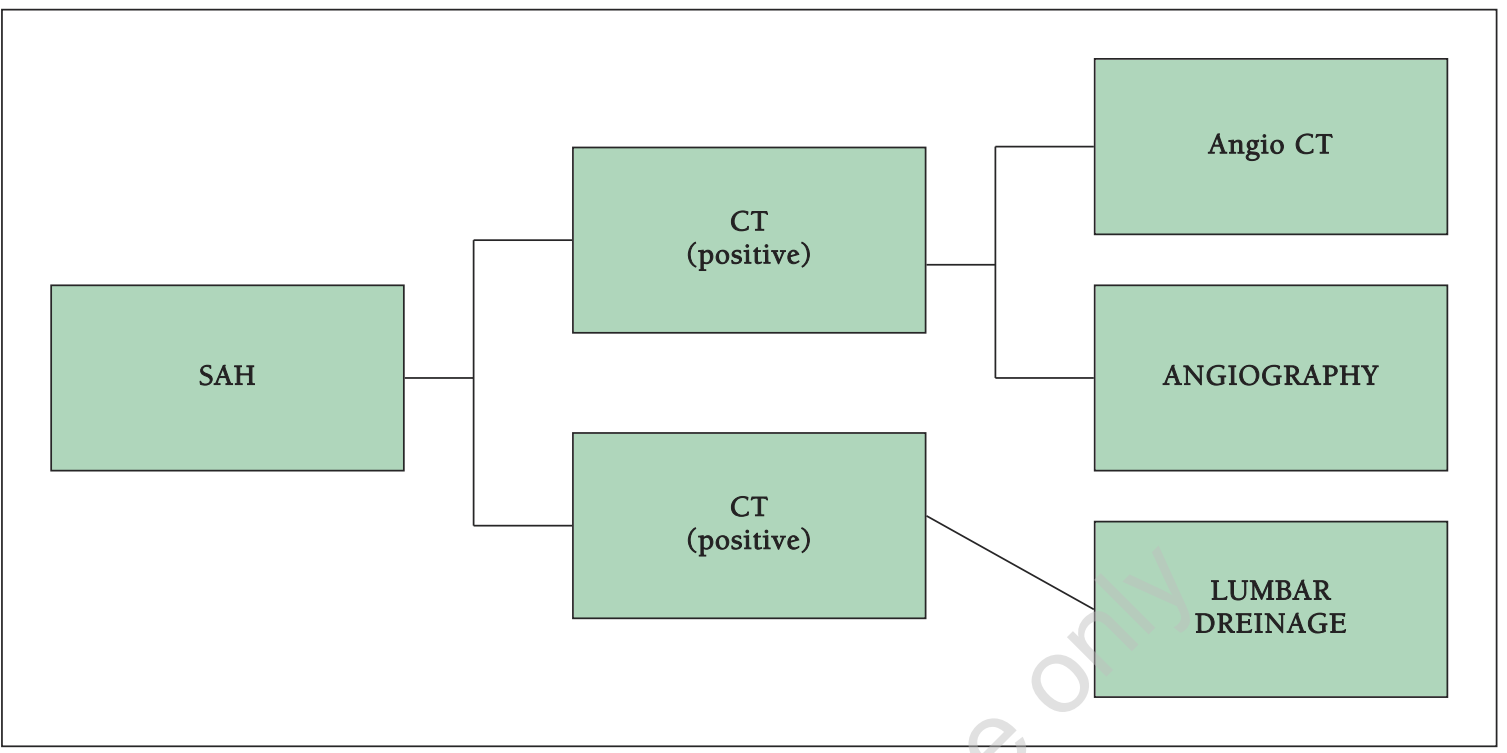

Fig. 1. Flow-chart for ESA patients management.

MRI techniques using proton-density-weighted images or fluid-attenuated inversion recovery images should be used but have some practical limitations: long time of acquisition, difficulty of scanning for a painful patient, motion artifacts and costs. Therefore, MRI is not used in acute SAH. Nevertheless, MRI is useful in identifing a former bleeding. Conventional catheter angiography remains the gold standard for detection of intracranial aneurysms. Angiography is not an innocuous procedure and it shows a complication rate of $1.8 \%$. Moreover, aneurysms can bleed during angigraphy, as occurs in $1-2 \%$ of cases (12). The aneurysm rupture rate during $6 \mathrm{~h}$ period after angiography is near $5 \%$ which is higher than the rate of the group that did not (12). A CT-angiography is usually performed at the admittance to investigate the presence of a vascular disease. Afterwards, in case of negative CT-angiography or if an endovascular treatment is favourable, a conventional angiography is performed (Fig. 1). If a source of bleeding has not been identified, the incidence of rebleeding is very low, especially if the blood is limited to the pretruncal cisterns $(5,13)$.

- CT: in any case (I choice).

- CT-angiography: in any case - where it is possible (I choice).

- ANGIOGRAFY: negative CT-angiography or possible endovascular treatment (II choice).

- RMN: in selected patient with a delayed diagnosis (III choice).

\section{Patient care}

Focus point for patients with a suspected SAH in emergency unit:

- GCS less than 8: intubate and recover in intensive care unit;

- GCS more than 8: do not intubate and recover in neurosurgery unit;

- Consider elective intubation of agitated patients to facilitate performing safe and rapid angiography.

\section{Medical management}

A high cerebral flow must be kept to ensure proper brain perfusion:

- Normovolemia;

- High blood pressure ( $>130 / 90 \mathrm{mmHg}$ );

- $\mathrm{ICP}<20$ mmHG.

Moreover, the occurence of seizures must be avoided using anticonvulsivant drugs (8).

Intensive care unit

- Arterial line (if hemodynamically unstable).

- Schwan-Ganz catheter (if hemodynamically unstable or HH more than 3). 
Table 2. The scale of severity described by Hunt and Hess in 1968.

HUNT and HESS scale:

1. asymptomatic, or mild headache and slight nucal rigidity;

2. cranial nerve palsy, moderate to severe headache, nucal rigidity;

3. mild focal deficit, lethargy, or confusion;

4. stupor, moderate to severe hemiparesis, early decerebrate rigidity;

5. deep coma, decerebrate rigidity, moribund appearance.
Table 3. The WFNS classification uses GCS and focal neurological deficits to gauge severity of symptoms.

\section{WFNS 1988 scale:}

1. GCS 15, motor deficit;

2. GCS $13 \mathrm{O} 14$, no motor deficit;

3. GCS 13 o 14 , motor deficit;

4. GCS 7-12, \pm motor deficit;

5. GCS 3-6, \pm motor deficit.

- Cardiac rhythm monitoring.

- Neuroprotection (drugs are debated).

- Pupils monitoring.

\section{Neurosurgery unit}

- Pressure monitoring.

- Cardiac rhythm monitoring.

- Neurological assessment.

The patient's status is evaluated using the Hunt and Hess Scale (Table 2) (14) and the World Federation of Neurologic Surgeons Scale (Table 3) (15).

Agitated patients must be intubated to perform safe and rapid angiography. Blood pressure control is often needed after SAH because of pain and generalized sympathetic activation. Blood pressure control prevents aneurysmal rerupture. Analgesics drugs alone may be effective, otherwise rapidly acting antihypertensives are needed.

Antihypertensives: The preferred agents include labetalol, beta blockers, hydralazine, and nicardipine. A vigorous treatment of hypertension is not indicated, expecially when hydrocephalus is present. In that situation blood pressure should be addressed after the hydrocephalus is treated to maintain an adequate brain perfusion.

Anticonvulsants: The risk of seizure in SAH is not defined. It is unclear whether abnormal movements at the time of aneurysm rupture are epileptic. Patients with parenchymal hematoma associated with SAH have an increased epileptic risk (8). Recently, the routine use of anticonvulsants has been associated with cognitive impairment in patients with SAH and heralded the growing acceptance of reduced use of anticonvulsants. Short term (3 day) use during the perioperative period does not increase risk of seizures (16).

Cerebral complications of a SAH include recurrent intracranial hemorrhage, vasospasm, cerebral infarction, hydrocephalus, cerebral edema, and intracranial hypertension.

Extracerebral early complications include respiratory failure, derangements of water and electrolyte homeostasis, myocardial dysfunction, sepsis, and thromboembolism.

The highest rebleeding rate is observed immediately following hemorrhage ( $4 \%$ to $6 \%$ during day 1 ) and declines over the next days (3). The daily risk of rebleeding is $2.6 \%$ on day $0,2.1 \%$ on day $1,0.3 \%$ on day $2,0.7 \%$ on day 3 , and $0.1 \%$ from day 4 (17). The rates are higher in women and those with a poor clinical grade, in poor medical condition, and with elevated systolic blood pressure. Rebleeding lead to death over 50\% of patients. Antifi-brinolytic agents were routinely administered some years ago to prevent re-bleeding (18). They succeeded in reducing the incidence of rebleeding but growing the risk rate of ischemic infarctions. Therefore, the impact on long-term outcome was poor. Some authors suggest a short term (3day) use of antifibrinolytics. Such therapy may prevent rebleeding without increased risk of vasospasm (19). Rapid drainage of large volume of cerebrospinal fluid during lumbar puncture or ventriculostomy should be avoided because a rapid pressure modification could lead to a rebleeding.

Patients should be sedated with short-acting agents to the point of drowsiness if they are agitated, but, they should remain responsive for assessment of neurologic status. In case of unresponsive patient intubation must be performed. Care must be taken to avoid oversedation that could mask clinical deterioration.

The only effective prevention of rebleeding is repair the aneurysm. Choosing the right way with surgical or an endovascular approach. Outcome in a large prospective controlled trial found that for patients appropriate for either modality, 4-year outcome was better with endovascular coiling (19). The study generated considerable controversy. Follow-up of patients enrolled in this study revealed that patients treated with endovascular coiling were 6.9 times more likely to undergo retreatment over a mean interval of 21 months because of aneurysm recurrence or rebleeding (20).

Early (within 3 days) hydrocephalus occurs in $20 \%$ to $30 \%$ of patients and is often accompanied by intraventricular blood. Hydrocephalus is more frequent in patients with poor clinical grade and more subarachnoid blood. Clinical improvement 


\section{clinica e terapia}
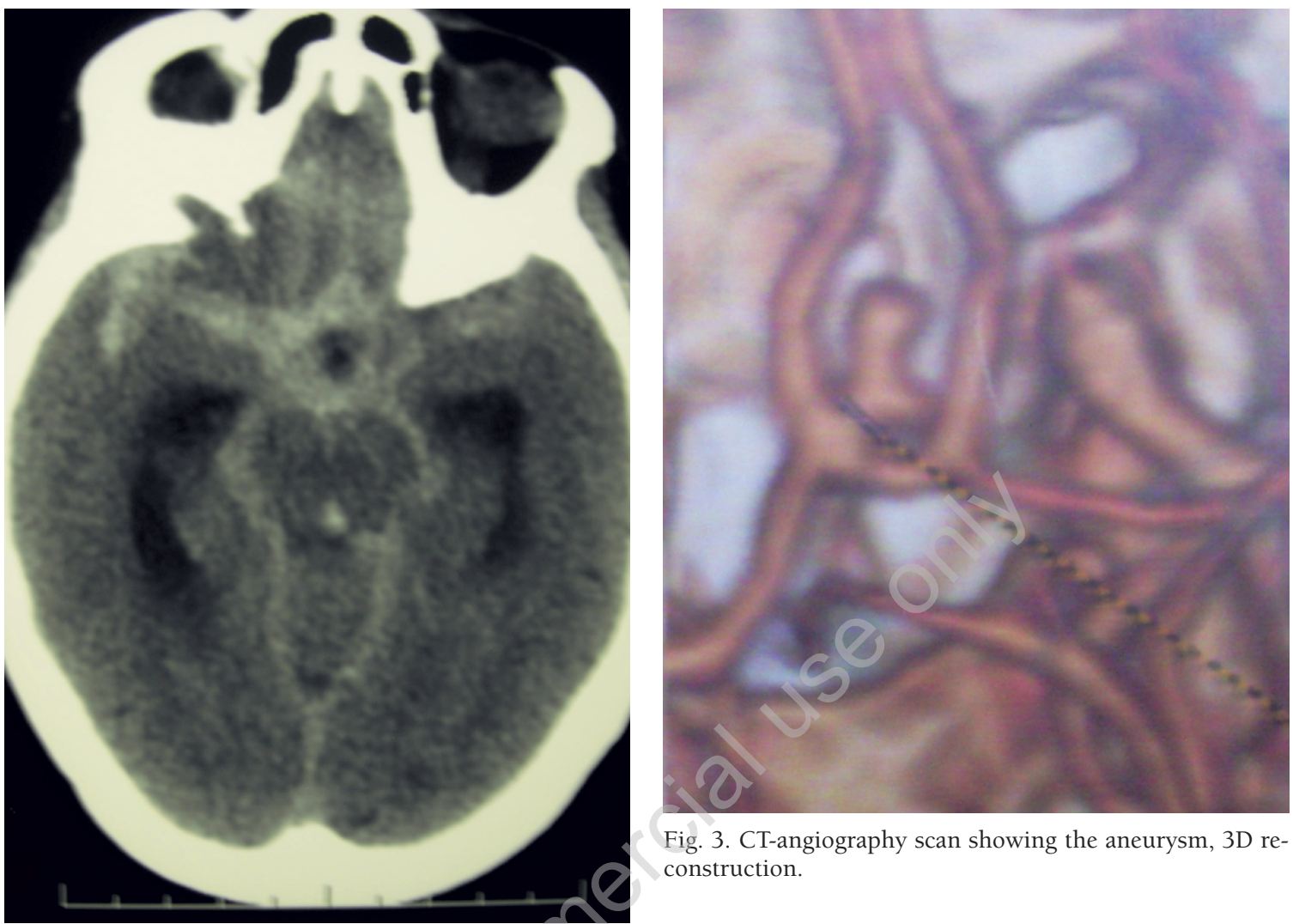

Fig. 3. CT-angiography scan showing the aneurysm, 3D reconstruction.

Fig. 2. CT scan showing a diffuse SAH., axial view.

is observed after external ventricular drainage. Delayed (up to several weeks) hydrocephalus develops in about $25 \%$ of surviving patients and is associated with older age, early ventriculomegaly, ventricular hemorrhage, poor clinical conditionon at admission, and female gender. Hydrocephalus rates are not different in patients undergoing clipping or endovascular treatment.

Vasopasm is a dreadful complication of SAH associated with an important mortality and morbidity. $10 \%$ to $30 \%$ people with SAH may be affected and show long-term related neurological deficits. Vasospasm depends on vasoconstrictor substances released after SAH all around the arterial walls and may be diffuse at the basal arteries or only restricted to the leading vessel. Stroke event may occur after vasospasm and it can damage the cerebral areas vascularized by the involved artery.

Diagnosis is based on signs and symptoms. Doppler US can be used to detect asymptomatic patients and CT-angiography may be used to confirm a strong suspicion.

Prevention is based on the "3H therapy" (hypervolemia, hypertension, hemodilution) that may be reached using Calcium antagonists (i.e. nimodipine) and hydration. An endovascular treatment is reserved for severe vasospasms.

A good outcome can be achieved with a rapid and appropriate management of either the acute event and the peri-operative complications. A long-term follow-up is generally required to rule out the risk of recanalization.

\section{Case report I}

A 50-year old man presented moderate headache and slight nucal rigidity with no neurological deficit (HH grade 1; WFNS grade 1). He was admitted to the emergency room of our hospital. The cerebral CT showed a SAH in the basal cistern and in the right sylvian fissure with an average thickness of $15 \mathrm{~mm}$ (Fisher grade 3 - Fig. 2). The CT-angiography showed an aneurysm of the anterior communicating artery (Fig. 3). The clinical data and the aneurysm features suggested to prefer a surgical approach than an endovascular procedure. Therefore, a six vessels angiography was performed to plan the clipping. The surgery was uneventful. Afterwards, the patient was admitted to the neurosurgical division for the post-operative care. 


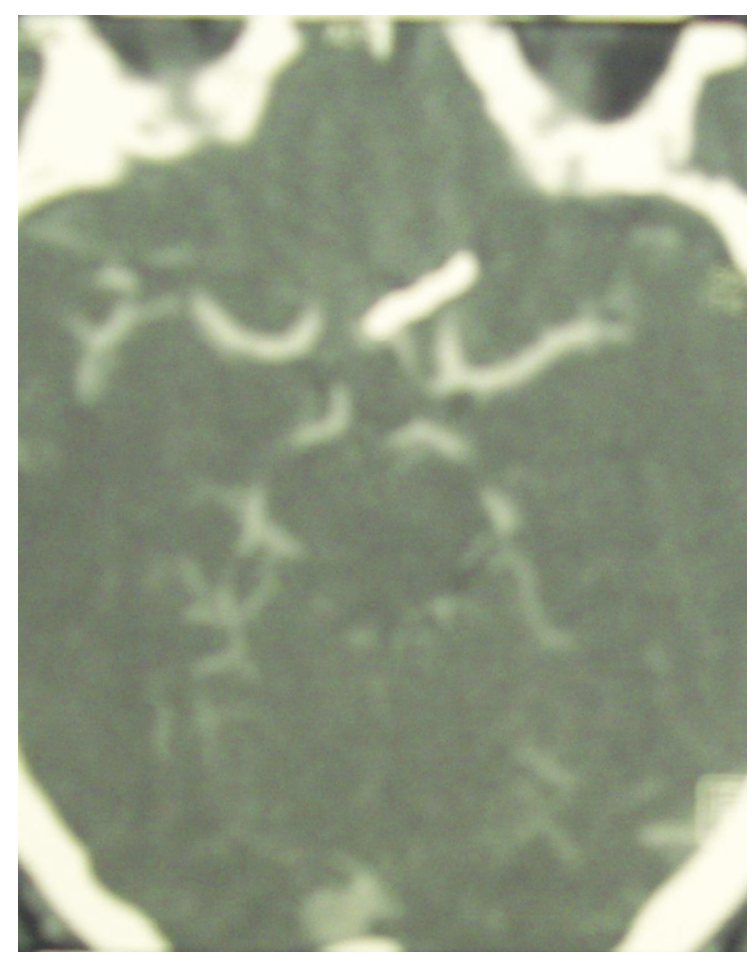

Fig. 4. Post-operative (clipping) CT-angiography scan showing the aneurysm exclusion, axial view..

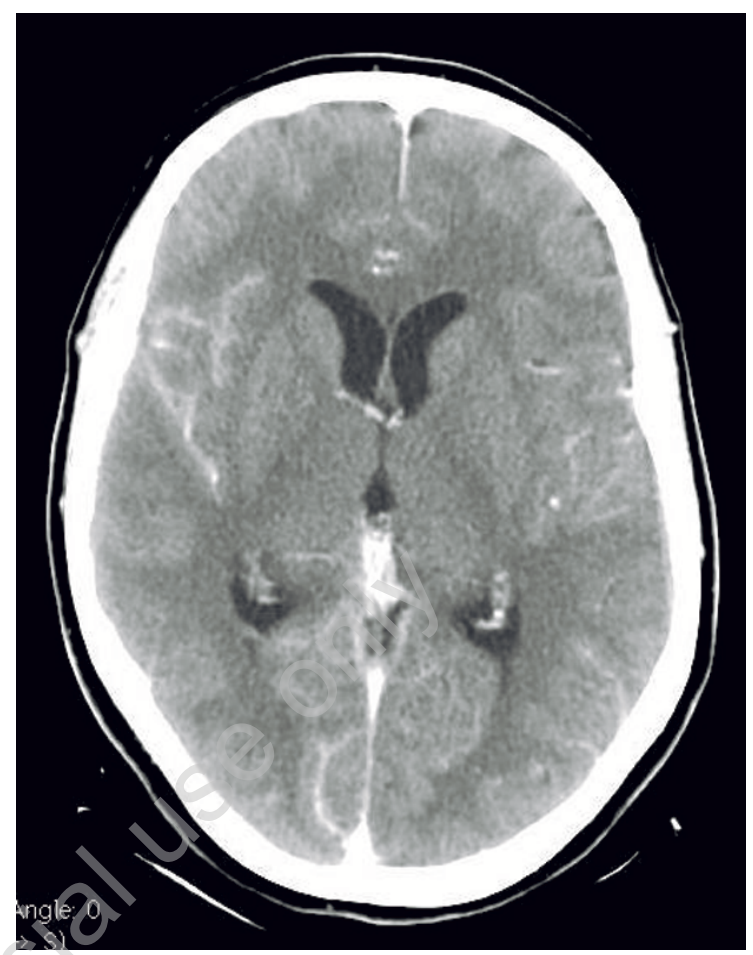

Fig. 5. CT scan showing a diffuse SAH, axial view..

A transcranial doppler-US every 3 days and 2 CT-angiographies were performed. Vasospasm and hydrocephalus were not observed. The patient was discharged at home two weeks later with no neurological deficit.

A CT-angiography performed 6 months later as a long-term check-up, showed the permanent exclusion of the aneurysm (Fig. 4).

\section{Case report 2}

The second case we report concern about a 48 years old woman. She came in hospital suffering from headache and vomiting. No motor defict, (hunt and hess score 1, WFNS 1, GCS 15). The TC performed showed diffuse thin hemorrhage around basal cisterns and right silvian fissure (Fig. 1). At the same time angio CT showed 2 aneurysms. The first one belonged to right internal carotid, 8,5 mm diameter, the second one belonged to left internal carotid and was 3 mm diameter (Fig. 6). Angiography was performed for a more accurate study of the cerebral circulation. Concerning with endovascular team the decision was surgery for the bigger aneurysm. Age, diameter and type of aneurysms were widely considered. Recovery was good during the whole period. The post-operative angio CT showed the exclusion of the right ICA aneurysm (Fig. 7). After 6 days an angio CT performed after a positive transcranial Doppler showed vasospasm of the right medium cerebral artery, without clinical signs. Left small aneurysm was treated by endovascular coiling. Patient presents no deficit with a good outcome.

\section{References}

1. Broderick J P, Brott T G, Tomsick et al. Intracerebral hemorrhage more than twice as common as subarachnoid hemorrhage. J Neurosurgery 1993; 78: 188-91.

2. Ingall T, Asplund $\mathrm{K}$, Mahonen M, et al. A multinational comparison of subarachnoid hemorrhage epidemiology in the WHO MONICA stroke study. Stroke 2000; 31: 1054-61.

3. Epidemiology of aneurysmal subarachnoid hemorrhage in Australia and New Zealand: Incidence and case fatality from the Australasian Cooperative Research on Subarachnoid Hemorrhage Study (ACROSS). Stroke 2000; $31: 1843.50$.

4. Qureshi AI, Suri MF, Yahia AM, et al. Risk factors for subarachnoid hemorrhage. Neurosurgery 2001; 49: 607,12. 


\section{clinica e terapia}

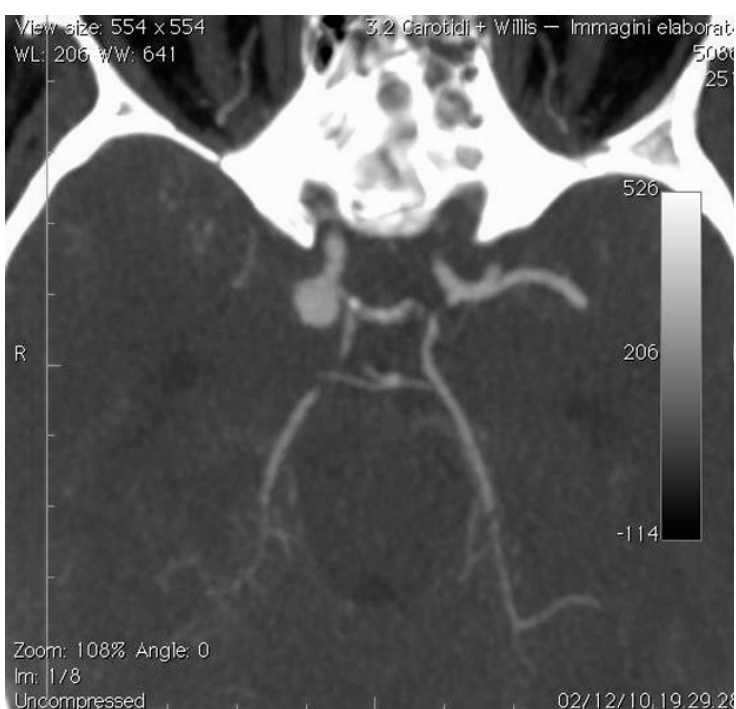

Fig. 6. CT-angiography scan showing a right ICA and a left ICA aneurysms, axial view.

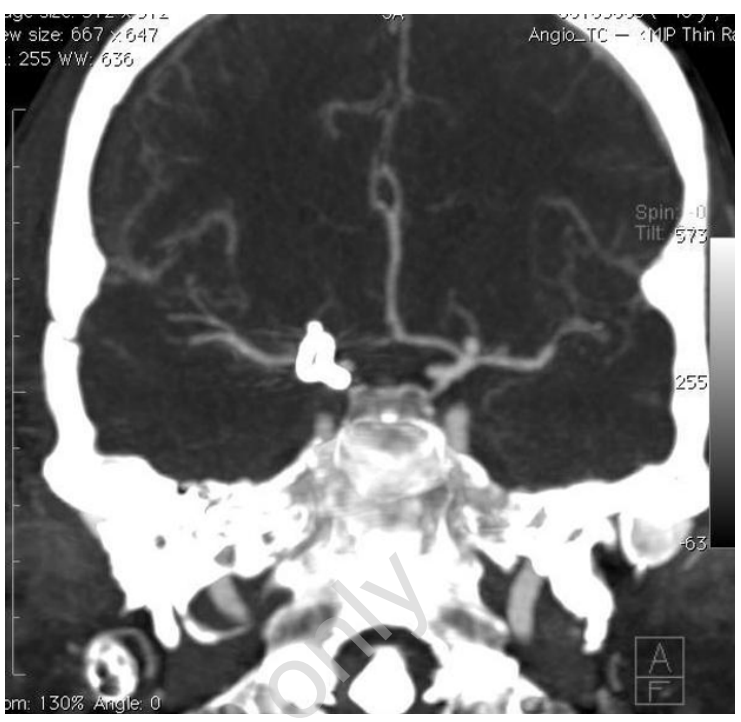

Fig. 7. Post-operative (clipping) CT-angiography scan showing the right ICA aneurysm exclusion, coronal view.

5. Van Gijn J, Kerr RS, Rinkel GJ. Subarachnoid haemorrhage. Lancet 2007; 369: 306-18.

6. Nehls DG, Flom RA, Carter LP, et al. Multiple intracranial aneurysms: determining the site of rupture. J Neurosurg 1985; 63: 342-8.

7. Sekhar LN, Heros RC. Origin, growth, and rupture of saccular aneurysms: A review. Neurosurgery 1981; 8: 248-26.

8. Hart RG, Byer JA, Slaughter JR, et al. Occurrence and implications of seizures in subarachnoid hemorrhage due to ruptured intracranial aneurysms. Neurosurgery 1981; 8: 417-21.

9. Morgenstern LB, Luna-Gonzales H, Huber JC Jr, Wong SS, Uthman MO, Gurian JH, et al. Worst headache and subarachnoid hemorrhage: prospective, modern computed tomography and spinal fluid analysis. Ann Emerg Med 1998; 32: 297-304.

10. van der WN, Rinkel GJ, Hasan D, et al. Detection of subarachnoid haemorrhage on early CT: Is lumbar puncture still needed after a negative scan? J Neurol Neurosurg Psychiatry 1995; 58: 357-59.

11. Fisher C, Kistler J, Davis J. Relation of cerebral vasospasm to subarachnoid hemorrhage visualized by computerized tomographic scanning. Neurosurgery 1980, 6: 1-9.

12. Koenig GH, Marshall WH Jr, Poole GJ, Kramer RA. Rupture of intracranial aneurysms during cerebral angiography: report of ten cases and review of the literature. Neurosurgery 1979; 5: 314-24.

13. Ruigrok YM, Rinkel GJ, Buskens E, et al. Perimesencephalic hemorrhage and CT angiography: A decision analysis. Stroke 2000; 31: 2976-83.

14. Hunt WE, Hess RM. Surgical risk as related to time of intervention in the repair of intracranial aneurysms. J Neurosurg 1968; 28: 14-20.

15. Report of World Federation of Neurological Surgeons Committee on a Universal Subarachnoid Hemorrhage Grading Scale. J Neurosurg 1988; 68: 985-6.

16. Chumnanvej S, Dunn IF, Kim DH. Three-day phenytoin prophylaxis is adequate after subarachnoid hemorrhage. Neurosurgery. 2007; 60: 99-102.

17. Roos YB, Rinkel GJ, Vermeulen M, et al. Antifibrinolytic therapy for aneurysmal sub-arachnoid haemorrhage. Cochrane Data- base Syst Rev 2003; 2:CD001245.

18. Naidech A, Janjua N, Kreiter K, Ostapkovich N, Fitzsimmons B, Parra A, et al. Predictors and Impact of Aneurysm Rebleeding After Subarachnoid Hemorrhage. Arch Neurol 2005; 62: 410-41.

19. De Oliveira JG, Beck J, Ulrich C, et al. Comparison between clipping and coiling on the incidence of cerebral vasospasm after aneurysmal subarachnoid hemorrhage: A systematic review and meta-analysis. Neurosurg Rev 2007; 30: 22-30.

20. Campi A, Ramzi N, Molyneux AJ, et al. Retreatment of ruptured cerebral aneurysms in patients randomized by coiling or clipping in the International Subarachnoid Aneurysm Trial (ISAT). Stroke 2007; 38: 1538-44. 